NOTICE: The Version of Record of this manuscript has been published and is available in Contemporary Nurse 2014;48(2):219-28. doi:10.5172/conu.2014.48.2.219

New graduate nurse transition programs: Relationships with bullying and access to support

Kathy L. Rush, Monica Adamack, Jason Gordon, and Robert Janke

Kathy L. Rush, PhD, RN, is Associate Professor, Graduate Program Coordinator, School of Nursing, University of British Columbia Okanagan, Kelowna.

Monica Adamack, MA, BSN, is Regional Practice Leader, Clinical Professional Education, Professional Practice Office, Kelowna, BC.

Jason Gordon, MHS, BScPT, is Project Coordinator, School of Nursing, University of British Columbia Okanagan, Kelowna.

Robert Janke, MLIS, BA, is Learning Services Librarian, University of British Columbia Okanagan, Kelowna. 


\begin{abstract}
New graduate nurses are often targets of bullying and horizontal violence. The support offered by new graduate nurse transition programs may moderate the effects of bullying and limit its negative impact on new graduate nurse transition. This study examined the relationships between access to support, workplace bullying and new graduate nurse transition within the context of new graduate transition programs. As part of a mixed methods study, an online survey was administered to new graduates $(\mathrm{N}=$ 245) approximately a year from starting employment. Bullied new graduate nurses were less able to access support when needed and had poorer transition experiences than their non-bullied peers. Participation in a formal transition program improved access to support and transition for bullied new graduate nurses. People supports within transition programs positively influenced the new graduate nurse transition experience. Formal transition programs provide support that attenuates the impact of bullying on new graduate nurses and improves transition.
\end{abstract}




\section{New graduate nurse transition programs: Relationships with bullying and access to support}

New nurse graduates' transition to practice is considered to be as challenging today as almost 40 years ago when Kramer (1974) termed the transition a reality shock. New graduate nurses are expected to assume an expanded role that often involves new and unfamiliar expectations for clinical and interpersonal competence. This transition is especially overwhelming when the workplace environment is not supportive but rather is characterized by horizontal violence and bullying (Kramer, Brewer, \& Maguire, 2011). Transition programs have emerged to facilitate transition by providing new graduate nurses with a supportive and nurturing learning environment and with improved access to support people and resources. Whether new graduate programs enhance new nurses' perceptions of support and mitigate negative work environments (eg. bullying and harassment) is currently unknown. The purpose of this study was to examine the relationships between access to support, workplace bullying and new graduate nurse transition within the context of new graduate transition programs.

\section{Support}

Support has been identified as key to successful transition of new graduates (Levett-Jones \& FitzGerald, 2005). Clarke and Springer (2012) described new graduates who felt valued and supported as having greater professional satisfaction and overall commitment to the organization. Transition programs designed specifically for new graduates have been described in terms of support because of the additional educational and people resources they make available to facilitate integration. In their qualitative study, Johnstone, Kanitsaki, and Currie (2008) found that appropriate support tailored to new graduates in a transition program allowed them to progress from novice to advanced beginner level practitioner within three to four months. The value of people supports/resources, such as preceptors, mentors, and peers, has been highlighted in a number of qualitative studies related to new graduate transition (Kaihlanen, Lakanmaa, \& Salminen, 2013; Kary, 2012). In her integrative review of the literature Kary (2012) found that preceptor support that was constant and consistent was key for new graduates during orientation. New graduates who did not have consistent preceptors felt less supported (Johnstone et al., 2008). Kaihlanen et al. (2013) found that mentors served as role change supports by identifying with the role of being a new graduate and sharing personal experiences about adjusting to work life. 
Staff and peer support have been shown to be important to new graduate transition. New graduates who remained in their acute care practice after two years of employment indicated that the sense of community and support they felt on their hospital units was the biggest contributor to their retention (Zeller, Doutrich, Guido, \& Hoeksel, 2011). Yet new graduates have described a lack of acceptance and respect, and an insensitivity of experienced nurses to their needs for continued development in time management skills (Casey, Fink, Krugman, \& Propst, 2004). Transition programs that have provided peer support opportunities for new graduates to meet and discuss their transition experiences have assisted new graduates in coping with the stress and emotions experienced during transition and to offer moral support (Keller, Meekins, \& Summers, 2006; Fink, Krugman, Casey, \& Goode, 2008). Few studies have addressed the relationship between access to support and new graduate transition experiences and whether it differs between new graduates participating in a new graduate program and those not participating in a program.

\section{Bullying and Horizontal Violence}

Although new graduates expect support they may not always receive it. They often experience horizontal violence and bullying, a trend reported in the nursing literature for more than two decades (Woelfle \& McCaffrey, 2007). Prevalence rates ranging from $33 \%$ to over $50 \%$ have been reported among new graduate nurses (Clare \& Loon, 2003; Laschinger, Grau, Finegan, \& Wilk, 2010; McKenna, Smith, Poole, \& Coverdale, 2003). Despite numerous anecdotal reports of new graduate bullying in current healthcare settings (Boychuk Duchscher \& Cowin, 2004; Randle, 2003), there has been limited empirical study of new nurse bullying (McKenna et al., 2003). McKenna et al (2003) found that over half of new graduate respondents had experienced covert interpersonal conflict and over a third reported barriers to learning opportunities, neglect, or excessive responsibility without appropriate support. Another third reported distressing overt interpersonal conflict in the form of verbal remarks that were rude, abusive, humiliating or involved unjust criticism.

New graduates are often the targets of bullying by more experienced nurses, because of their position and junior status within the organizational hierarchy. New graduates in one phenomenological study experienced bullying and horizontal violence as power games, hierarchy and 'bitchiness' that shattered their ideal view of belonging to a noble profession (Kelly \& Ahern, 2009). In their Australian 
qualitative descriptive study, Evans, Boxer, and Sanber (2008) similarly found that most of the new graduates $(n=9)$, and nurses $(n=13)$ who worked with them during their transition program, described bullying or horizontal violence that primarily targeted those lower in the hierarchy, who were less experienced, worked casual, and were viewed as 'not up to scratch.' Whether participation in a transition program mitigates the impact of bullying for new graduates is unknown since few studies have compared program with non-program participants.

\section{Support, Bullying, and New Graduate Transition}

Horizontal violence and workplace bullying threaten new graduates' adjustment to an increased scope of practice (Laschinger et al., 2010). At the very critical time of transitioning to their RN role when stress levels are already high, bullying may undermine confidence and interfere with new graduates' developing competency and skill consolidation (McKenna et al., 2003). In a study of novice nurses, who had been in practice for less than two years, researchers found that bullying had a strong relationship to decreased work productivity (Berry, Gillespie, Gates, \& Schafer, 2012). Johnstone et al. (2008) found that being treated as "naturally incompetent," "inferior to others," and as "perpetual students" was the most potent barrier to new graduate nurse support and made it difficult for graduates to ask for help and support if it was needed. Help that is not sought when it is needed can cause errors, accidents, and poor work performance (Woelfle \& McCaffrey, 2007).

Although not specific to new graduates, Quine (2001) found that a supportive work environment moderated some of the harmful effects of bullying. Nurses who reported being bullied but had good support at work had significantly lower scores on the propensity to leave and depression scales and higher scores for job satisfaction than those who reported being bullied but had poor support. New graduate transition programs are designed to provide support that might offset effects of bullying and improve transition. No studies have examined the role of support within the context of new graduate transition programs and its impact on bullying and the new graduate's transition experience.

\section{Research Questions}

The purpose of this study was to examine the relationships between access to support, workplace bullying and new graduate nurse transition experience within the context of new graduate transition programs. Access to support was defined as new graduates' perceptions of available people 
resources when they needed them. Bullying was defined as perceived negative and hurtful acts directed at new graduates. New graduate transition was new graduates' self-reported perceptions of the quality of the transition experience. Within the context of this study there was no standardized province-wide New Graduate Nurse Transition Program due to geographical, financial and hiring pattern variances. Formal transition programs were characterized by similar elements across the seven Health Authorities and typically involved an orientation and transition phase. The orientation phase included an organization / regional orientation (up to 4 hours), followed by a one to four day nursing department orientation, and 96 to 144 hours of supernumerary (preceptored/buddied) shifts. The Transition phase included periodic educational sessions (one to six days ranging from 4 hours to 7.5 hours each) and formal/informal pairing with a mentor, who provided non-evaluative support that in some cases occurred for up to a year following graduation. The following questions guided the study:

Question 1: When do new graduate nurses participating in a formal transition program perceive the greatest need for support during their transition compared to nurses not participating in a program? Are new graduate nurse participants in a formal transition program better able to access support when they perceive the greatest need for support compared to non-participants?

Question 2: What people supports are the most helpful for new graduate nurses participating in a formal transition program? For these nurses, what is the relationship between the quality of the transition experience and the helpfulness ranking of support people?

Question 3: What is the prevalence of self-reported bullying between new graduate nurses participating in a formal transition program compared to non-participating new graduate nurses?

Question 4: For new graduate nurses, what is the relationship between the transition quality and the predictors "ability to access support when most needed", "bullying/harassment" and "transition program participation"?

\section{Methods}

\section{Design}

The findings reported here are part of a larger mixed methods study designed to provide a comprehensive assessment of new nurse graduate transition best practices from the perspective of multiple stakeholder groups (Doyle, Brady, \& Byrne, 2009). The study was conducted in selected 
hospitals, across seven health authorities operating within the western Canadian province of British Columbia. The quantitative arm of the study used an online survey administered to new graduates approximately a year after starting employment. Part of the survey findings are reported in this paper.

\section{Sample}

Following approval from the Ethics Review Boards of two universities (UBC Okanagan H1100444) and seven provincial health authorities, sample recruitment began. The population from which the sample was recruited included all new graduate nurses (graduating class of 2010) from the seven health authorities in British Columbia who were within one year of employment in an acute care setting. Representatives working in new graduate transition from each health authority identified eligible study participants. Recruitment of the sample for the survey component occurred by e-mail using mechanisms internal to each health authority.

\section{Data Collection}

Prior to administration, the online survey (the Canadian-based company, Fluid Surveys) was pilot tested with nine participants for clarity of instructions and items, readability, and time to completion. Subsequently minor revisions were made. New graduates received e-mail notification about the study which included a letter of information, an invitation to participate, and a link to access the online survey from their work electronic mail. The letter of introduction and consent to participate in the survey included information regarding eligibility criteria, risks, benefits, confidentiality, anonymity, consent, and investigator contact information. The online survey, which took approximately 15 minutes to complete, asked new graduates questions about their orientation and transition including participation in a new graduate transition program. Each eligible new graduate nurse was sent at least one follow-up email reminder. Participant consent was implied via survey completion.

\section{Instrumentation}

The online survey consisted of five sections: demographics, orientation to the employer and to the nursing unit, general transition, participation in a formal new graduate nurse transition program, and the Casey-Fink Graduate Nurse Experience Survey (Casey, Fink, Krugman, \& Propst, 2004). Demographic questions elicited information related to age, gender, employment/work status, and previous health work experience. Orientation questions asked if new graduates had received one, its 
length, and percentage of preceptored shifts. General transition questions asked new graduates when they experienced the greatest need for support, how often they were able to access support during their greatest need, and if they had experienced any bullying and/or harassment in the workplace as a new graduate nurse. Specific transition program questions asked about program length, and the helpfulness of educational and people resources.

The Casey-Fink survey instrument, originally developed in 1999 and revised in 2002, was utilized to quantify a new graduate nurse's transition experience (Goode, Lynn, Krsek, \& Bednash, 2009). Used extensively with US new graduates working in hospital settings, it is a 24-item, 4-point summative scale, consisting of 5 subscales - organizing/prioritizing, communication/leadership, support, stress, and professional satisfaction (Casey et al., 2004). Total transition scores were derived by summing the scores for all 24 questions of the survey while relevant subscale items were totalled to derive subscale scores. Higher total and subscale transition scores reflected better transition. In the current study, four of the multi-item transition subscales showed convergent and divergent validity; the single stress subscale could not be assessed. The subscales demonstrated satisfactory or nearly satisfactory Cronbach's alpha internal consistency reliability - priority setting/organizing subscale (.75), communication/leadership subscale (.70), support subscale (.83), and professional satisfaction subscale (.69), approximating those reported in other studies.

\section{Quantitative Analysis}

Quantitative data were analyzed using descriptive and inferential statistics. Descriptive statistics were used to summarize data about the sample of new graduate nurses. Simple linear regression modeling was used to elucidate the relationship between the total and subscale transition scores and the helpfulness ranking of support people. Multiple linear regression analyses were conducted to investigate the relationship between the total/subscale transition score and the predictors "transition program participation", "ability to access support when most needed", and "bullying/harassment" followed by conditional effect plots. For these analyses, the values of the predictor "ability to access support when needed" were coded as 1 = "None/some of the time", 2 = "Most of the time" and 3 = "All of the time". With this coding in place, "ability to access support when needed" was treated as a numerical predictor. The predictor "bullying/harassment in the workplace" was considered dichotomous, with the levels "Yes" and 
"No". All statistical analyses were conducted using the open source statistical software package R version 2.13.0 (R Development Core Team, 2012). The level of statistical significance for all analyses was set at $\mathrm{p}<.05$.

\section{Findings}

\section{Description of Sample}

A description of the nurses who completed the online survey $(n=245)$ appears in Table 1. Of the 245 nurses, more than half (54.7\%) were aged $25-35$ and the majority $(90.6 \%)$ were females. Nearly $40 \%$ of the nurses had been employed from 6 months to 1 year and just over $46 \%$ of the nurses had been employed for more than 1 year. Most nurses had previous health care experience via an Employed Student Nurse Program (56.7\%) or other health related employment (30.6\%). Sixty percent of the nurses worked between 49-80 hours on average over a two-week period.

\section{Need For and Access to Support}

A little over $60 \%$ of new graduate nurses, whether program or non-program participants reported their greatest need for support at one to three months post-graduation. While $81.3 \%$ of the new graduate nurses attending a formal transition program were able to access support when needed either most (52.1\%) or all (29.2\%) of the time, only $54.5 \%$ of the nurses who did not attend such a program were able to access support when needed either most $(41.6 \%)$ or all $(12.9 \%)$ of the time.

\section{Helpfulness of People Supports}

Table 2 provides the percentages of nurses attending a formal transition program $(n=142)$ who found various types of support people very helpful, moderately helpful to helpful or not very helpful during their transition process. The preceptor was identified as the most helpful source of support followed by unit staff, mentor and other new graduates/peers.

For nurses attending a formal transition program, significant positive linear relationships were found between the total transition score and the helpfulness ranking attributed to the preceptor, unit staff and mentor. In particular, a 1-unit increase in the value of the helpfulness ranking attributed to each of these people resources was found to be associated with increases in the expected values of the total transition scores: 1.14 points ( $95 \% \mathrm{Cl}: 0.09$ to 2.20$)$ for the preceptor resource, 3.99 points (95\% $\mathrm{Cl}: 1.82$ to 6.17$)$ for the unit staff resource and 1.10 points $(95 \% \mathrm{Cl}: 0.10$ to 2.09$)$ for the mentor resource. 
Only the support subscale score had a significant positive linear relationship with helpfulness ranking attributed to the preceptor, unit staff and mentor for nurses attending a formal transition program. Specifically, each 1-unit increase in the value of the helpfulness ranking attributed to each of these people resources was found to be associated with increases in the expected values of the support subscale scores: 0.82 points ( $95 \% \mathrm{Cl}: 0.27$ to 1.37$)$ for the preceptor resource, 2.87 points (95\% Cl: 1.82 to 3.91 ) for the unit staff resource and 0.87 points $(95 \% \mathrm{Cl}: 0.41$ to 1.32$)$ for the mentor resource.

\section{Self-reported Bullying and Transition Program Participation}

Thirty-nine percent of new graduate participants $\left(n=242^{1}\right)$ claimed they experienced bullying/harassment. The prevalence of bullying was the same among the 142 nurses who attended a formal transition program (39\%) and the 100 nurses who did not (39\%). Among the program participants, $69 \%$ of the bullied nurses were able to access support when needed most or all of the time compared to $90 \%$ for the non-bullied nurses. In contrast, among non-program participants $38 \%$ of the bullied/harassed nurses were able to access support when needed most or all of the time versus $64 \%$ for the non-bullied nurses.

\section{Program Participation, Self-Reported Bullying, and Support}

Transition program participation, ability to access support when most needed, and bullying/harassment accounted for $31.79 \%$ of the variability in the total transition scores of the new graduate nurses. According to Table 3, participation in a transition program was associated with higher total transition scores after taking into account bullying/harassment in the workplace and ability to access support when needed $(t=2.991, d f=239 ; P$-value $=0.00307)$. The mean value of the total transition score was 2.96 points higher for nurses who participated in a transition program compared to those who did not (95\% Cl: 1.01 to 4.90$)$, all else being equal.

When accounting for participation in a formal new graduate transition program, bullying/harassment in the workplace was found to be a statistically significant moderator of the relationship between new graduates' ability to access support when needed and their total transition scores $(\mathrm{t}=-2.527, \mathrm{df}=239 ; \mathrm{P}$-value $=0.01217)$. Higher values in total transition scores were associated

\footnotetext{
${ }^{1}$ Nurses who provided information on their formal new graduate transition program participation, bullying/harassment status, and ability to access support when most needed.
} 
with a greater ability to access support when needed for both the nurses who were bullied/harassed and those who were not. This positive relationship was weaker among nurses who were bullied/harassed, with each one-unit increase in their ability to access support when needed associated with a 2.90 point increase in the mean value of the total transition score $(95 \% \mathrm{Cl}: 0.77$ to 5.04$)$ compared to a 6.35 increase in scores of new nurses who were not bullied/harassed (95\% Cl: 4.61 to 8.09$)$ when controlling for transition program participation. (See Figure 1 for details). Statistically significant moderating effects of bullying/harassment were found on new graduates' ability to access support when needed and their organizing/prioritizing subscale score $(t=-3.717, d f=239$; $P$-value $=0.00025)$, and stress subscale score $(t=-2.050, d f=239 ; P$-value $=0.0414)$ after controlling for participation in a formal new graduate transition program.

\section{Discussion}

It was expected that new graduates participating in transition programs would experience greater access to support when they needed it, less bullying, and an enhanced transition experience. This expectation was partially supported with transition program participants better able to access support and showing greater improvement in transition than non-participants regardless of bullying status.

Over $60 \%$ of new graduates in this study reported that their greatest need for support was during months one to three, a time of greater vulnerability if they were unable to access support. Support was accessible none or only some of the time for nearly half of those who were bullied, putting them at greater risk of transition stress than their non-bullied colleagues. The one to three month period of heightened need for support contrasts with other studies indicating greater vulnerability of new graduates near the mid-point of their first year of transition when stress levels are the highest and job satisfaction the lowest (Bratt, 2009; Casey et al., 2004; Krugman, et al.,, 2006; Williams, Goode, Krsek, Bednash, \& Lynn, 2007). All but $12 \%$ of new graduates in the current study had had previous experience in health care, either as an employed student nurse or other health related employment, giving them familiarity with the culture and perhaps accounting for this more abbreviated period of need for greater support.

An important finding in the current study was the helpfulness of preceptors, unit staff nurses and mentors in supporting new graduates who participated in a transition program. In contrast to other work indicating the negative influence of unit staff's lack of acceptance and respect for new graduates (Casey 
et al., 2004) this study is unique in highlighting the positive impact supportive unit staff had on a new graduate's transition experience. The more helpful new graduates found their unit staff in supporting their transition, the more positive their transition experience. Although much attention has been given to the cultivation of one-on-one support for new graduates, such as preceptors and mentors, equally as valuable is a network of support at a unit level. Formal support should include the use of mentors throughout the duration of a formal transition program, and informal support through the facilitation of peer-support opportunities.

Thirty-nine percent of new graduates had experienced self-reported bullying and/or harassment, a figure comparable to that reported in other studies (Laschinger et al., 2010). An unexpected finding was that self-reported bullying was similar among new graduates whether or not they participated in a new graduate transition program. But those new graduates who experienced bullying/harassment had better transition scores if they participated in a formal transition program compared to bullied new graduates who did not. These findings suggest that the transition program provided a "layer of protection", shielding new graduates from the harmful culture of workplace bullying so that they could engage in the work of transition to professional practice. New graduates without this protective effect were clearly disadvantaged in their transition. Kramer et al. (2011) suggested that the focus on transition should be on adjusting to the workplace environment and not the role. Zero tolerance policies have been promoted to create healthy environments but their focus on the individual has reduced their effectiveness (Hutchinson, Jackson, Wilkes, \& Vickers, 2008). Supportive, collegial environments which promote respect, open communication and teamwork begin to create cultures where bullying is not fashionable (Rocker, 2008).

Findings from this study are among the first to show that bullying attenuated the relationship between new graduates' access to support and their transition, specifically in relation to organizing/ prioritizing, communication/relationships, stress, and professional satisfaction. Although new graduates with greater access to support had higher transition scores, those who were bullied did not make the rapid gains in transition that their non-bullied counterparts did. Bullied nurses regardless of their participation in a transition program were less able to access support than non-bullied new graduate nurses. The diminishing effect on transition as a result of bullying is of serious concern because it slows 
"doing" and skill development, which according to Boychuk Duchscher and Cowin's (2004) Transition Stages Model, is a critical milestone in the first three months of a new graduate's transition. Berry et al. (2012) suggest bullying impedes nurses' ability to concentrate on the complexity of tasks related to patient care. This may slow or interfere with the transition, which has consequences for both the new graduate and the institution. These findings resonate with those of Laschinger et al. (2010) who found that new graduates who reported less bullying had high workplace ratings and particularly access to resources. They speculated that greater resources allowed staff more time and patience to help new graduates learn their roles and accomplish their work tasks. Similar to Quine (2001) who found that good workplace support moderated the negative effects of bullying by improving retention, increasing job satisfaction, and decreasing depression, the current findings suggest that access to support facilitated transition especially for non-bullied new graduates.

\section{Limitations}

The data are limited by the use of self-report and absence of corroborating information. Regardless, new graduates' interpretations of bullying situations warrant attention to avert a negative impact on transition. It is unknown how non-program participants would have rated the helpfulness of "people supports" such as staff nurses or mentors who they might have sought out on their own. New graduate nurse survey respondents constituted a convenience sample and may not be representative of the new graduate nurse population so caution must be used in generalizing the findings.

\section{Conclusion}

Despite an increasing awareness of bullying within the nursing profession, the fact remains it continues to be a prevalent issue with serious implications. The decreased ability of bullied nurses to access support when needed compared to that of their non-bullied peers has a negative impact on their transition experience. Formal transition programs can provide a supportive work environment to assist bullied new graduate nurses through their transition process. These programs should include bullying prevention strategies as well as education/training for preceptors, unit staff and mentors to ensure they understand how to be a helpful resource to new graduate nurses. The length of transition programs could be tailored to account for the fact that nurses with previous health care experience need the most support around the one to three month period. 
References

Berry, P. A., Gillespie, G. L., Gates, D., \& Schafer, J. (2012). Novice nurse productivity following workplace bullying. Journal of Nursing Scholarship, 44(1), 80-87.

Boychuk Duchscher, J. E., \& Cowin, L. (2004). Multigenerational nurses in the workplace. The Journal of Nursing Administration, 34(11), 493-501.

Bratt, M. M. (2009). Retaining the next generation of nurses: The Wisconsin nurse residency program provides a continuum of support. Journal of Continuing Education in Nursing, 40(9), 416-425.

Casey, K., Fink, R., Krugman, M., \& Propst, J. (2004). The graduate nurse experience. The Journal of Nursing Administration, 34(6), 303-311.

Clare, J., \& Loon, A. (2003). Best practice principles for the transition from student to registered nurse. Collegian, 10(4), 25-31.

Clark, C. M. \& Springer, P.J. (2012). Nurse residents' first-hand accounts on transition to practice. Nursing Outlook, 60(4), 2-8.

Doyle, L., Brady, A., \& Byrne, G. (2009). An overview of mixed methods research. Journal of Research in Nursing, 14(2), 175-185.

Evans, J., Boxer, E., \& Sanber, S. (2008). The strengths and weaknesses of transitional support programs for newly registered nurses. Australian Journal of Advanced Nursing, 25(4), 16-22.

Fink, R., Krugman, M., Casey, K., \& Goode, C. (2008). The graduate nurse experience: Qualitative residency program outcomes. The Journal of Nursing Administration, 38(7-8), 341-348.

Goode, C. J., Lynn, M. R., Krsek, C., \& Bednash, G. D. (2009). Nurse residency programs: An essential requirement for nursing. Nursing Economic\$, 27(3), 142-148.

Hutchinson, M., Jackson, D., Wilkes, L., \& Vickers, M. (2008). A new model of bullying in the nursing workplace: Organizational characteristics as critical antecedents. Advances in Nursing Science, 32(2), 60-71.

Johnstone, M. J., Kanitsaki, O., \& Currie, T. (2008). The nature and implications of support in graduate nurse transition programs: An Australian study. Journal of Professional Nursing, 24(1), 46-53. 
Kaihlanen, A.-M., Lakanmaa, R.-L., \& Salminen, L. (2013). The transition from nursing student to registered nurse: The mentor's possibilities to act as a supporter. Nurses Education in Practice, 13(5), 418-422.

Kary, A. (2012). Supporting new graduates successful transition into practice through orientation in the emergency department: An integrative literature review (Master's thesis). Retrieved from http://hdl.handle.net/1828/4448

Keller, J. L., Meekins, K., Summers, B. L. (2006). Pearls and pitfalls of a new graduate academic residency program. Journal of Nursing Administration, 36(12), 589-598.

Kelly, J., \& Ahern, K. (2009). Preparing nurses for practice: A phenomenological study of the new graduate in Australia. Journal of Clinical Nursing, 18(6), 910-918.

Kramer, M., Brewer, B. B., \& Maguire, P. (2011). Impact of healthy work environments on new graduate nurses' environmental reality shock. Western Journal of Nursing Research, 35(3), 348-383.

Kramer, M. (1974). Reality shock; why nurses leave nursing. Saint Louis, MO: Mosby.

Krugman, M., Bretschneider, J., Horn, P. B., Krsek, C. A., Moutafis, R. A., \& Smith, M. O. (2006). The National Post-Baccalaureate Graduate Nurse Residency Program: A model for excellence in transition to practice. Journal for Nurses in Staff Development, 22(4), 196-205.

Laschinger, H. K., Grau, A. L., Finegan, J., \& Wilk, P. (2010). New graduate nurses' experiences of bullying and burnout in hospital settings. Journal of Advanced Nursing, 66(12), 2732-2742.

Levett-Jones, T., \& FitzGerald, M., (2005). A review of graduate nurse transition programs in Australia. Australian Journal of Advanced Nursing, 23(2), 40-44.

McKenna, B., Smith, N., Poole, S., \& Coverdale, J. (2003). Horizontal violence: Experiences of registered nurses in their first year of practice. Journal of Advanced Nursing, 42(1), 90-96.

Quine, L. (2001). Workplace bullying in nurses. Journal of Health Psychology, 6(1), 73-84.

Randle, J. (2003). Bullying in the nursing profession. Journal of Advanced Nursing, 43(4), 395-401.

Rocker, C. F. (2008). Addressing nurse-to-nurse bullying to promote nurse retention. The Online Journal of Issues in Nursing, 13(3). Retrieved from http://www.nursingworld.org

Williams, C. A., Goode, C. J., Krsek, C., Bednash, G. D., \& Lynn, M. R. (2007). Postbaccalaureate nurse residency 1-year outcomes. The Journal of Nursing Administration, 37(7-8), 357-365. 
Woelfle, C. Y., \& McCaffrey, R. (2007). Nurse on nurse. Nursing Forum, 42(3), 123-131. 


\section{Table 1.}

Sample description of new graduate nurses $(n=245)$

\begin{tabular}{|c|c|c|}
\hline Demographic Characteristic & Frequency & Percentage \\
\hline \multicolumn{3}{|l|}{ Age } \\
\hline Under 25 & 74 & 30.2 \\
\hline $25-35$ & 134 & 54.7 \\
\hline 36 or more & 36 & 14.7 \\
\hline Not reported & 1 & 0.4 \\
\hline \multicolumn{3}{|l|}{ Gender } \\
\hline Female & 222 & 90.6 \\
\hline Male & 18 & 7.3 \\
\hline Not reported & 5 & 2.0 \\
\hline \multicolumn{3}{|l|}{ Length employed } \\
\hline Less than 6 months & 31 & 12.7 \\
\hline 6 months to 1 year & 96 & 39.2 \\
\hline More than 1 year & 115 & 46.9 \\
\hline Not reported & 3 & 1.2 \\
\hline \multicolumn{3}{|l|}{ Previous health care experience } \\
\hline ESN Program & 139 & 56.7 \\
\hline Other health related employment & 75 & 30.6 \\
\hline No previous health related experience & 30 & 12.2 \\
\hline Not reported & 1 & 0.4 \\
\hline \multicolumn{3}{|l|}{ Employment status } \\
\hline Permanent full-time & 74 & 30.2 \\
\hline
\end{tabular}


Permanent part-time

Temporary full-time

Temporary part-time

Casual

Not reported

Average number of hours worked every 2 weeks

48 hours or less

49-80 hours

More than 80 hours

Not reported

Percentage of night shifts every 2 weeks

$25 \%$ or less

66

123

51

5
$26-50 \%$

More than $50 \%$

Not reported
12.2

13.9

6.5

36.7

0.4

28.2

60.0

10.6

1.2
69

147

26

3

Note: New graduate nurses who did not answer the demographics questions were listed under the category "Not reported" of each demographic characteristic. 


\section{Table 2.}

New nurses $(n=144)$ percentage ratings of helpfulness of types of people support.

\begin{tabular}{|lllll|}
\hline Types of Support People & $\begin{array}{l}\text { Very } \\
\text { helpful }\end{array}$ & $\begin{array}{l}\text { Helpful/ } \\
\text { Moderately } \\
\text { helpful }\end{array}$ & $\begin{array}{l}\text { Not very } \\
\text { helpful }\end{array}$ & $\begin{array}{l}\text { Not } \\
\text { applicable }\end{array}$ \\
\hline Preceptor & 60.8 & 16.1 & 1.4 & 21.7 \\
Mentor & 43.8 & 21.5 & 0.7 & 34.0 \\
Transition Program Coordinator & 18.8 & 50.7 & 16.7 & 13.9 \\
Clinical Educator & 27.8 & 52.1 & 13.2 & 6.9 \\
Other NGs/Peers & 38.2 & 53.5 & 2.1 & 6.2 \\
Unit Staff & 44.4 & 50.7 & 4.2 & 0.7 \\
\hline
\end{tabular}




\section{Table 3.}

Results of the multiple linear regression model relating the total transition score to the predictors "transition program participation", "ability to access support when needed", and "bullying/harassment". The model included one dummy variable for coding the effect of the dichotomous predictor variable "transition program participation" and one dummy variable for coding the effect of the dichotomous predictor variable "bullying/harassment". Both of these predictor variables were coded as "Yes" or "No", so their reference category was taken to be "No".

\begin{tabular}{|c|c|c|c|c|c|}
\hline Term & Coefficient & $\begin{array}{l}\text { Standard } \\
\text { Error }\end{array}$ & $\begin{array}{c}\mathbf{T} \\
\text { Value }\end{array}$ & P-Value & $95 \% \mathrm{Cl}$ \\
\hline \multicolumn{6}{|l|}{ Dummy Variable for } \\
\hline \multicolumn{6}{|l|}{ Transition Program Participation } \\
\hline Yes & 2.9566 & 0.9884 & 2.991 & 0.00307 & $(1.0095,4.9037)$ \\
\hline \multicolumn{6}{|l|}{ Dummy Variable for Bullying/Harassment } \\
\hline & 3.7050 & & 1.366 & 0.17312 & $(-1.6368,9.0467)$ \\
\hline Ability to Access Support when Needed & 6.3546 & 0.8833 & 7.194 & $<0.001$ & $(4.6146,8.0946)$ \\
\hline \multicolumn{6}{|l|}{ Interaction between } \\
\hline \multicolumn{6}{|l|}{ Bullying/Harassment and } \\
\hline Ability to Access Support when Needed & -3.4534 & 1.3668 & -2.527 & 0.01217 & $(-6.1459,-0.7608)$ \\
\hline (Constant) & 58.8502 & 1.8601 & 31.638 & $<0.001$ & $(55.1859,62.5145)$ \\
\hline \multicolumn{6}{|c|}{$31.79 \%,=30.65 \%$} \\
\hline \multicolumn{6}{|c|}{ Residual standard error: 7.222 on 239 degrees of freedom } \\
\hline \multicolumn{6}{|c|}{ F-statistic: 27.85 on 4 and 239 DF, P-value $<0.001$} \\
\hline
\end{tabular}




\section{Figure 1.}

Relationship between total transition score and ability to access support when needed among NGs who did not participate in a formal transition program, conditional on bullying status.

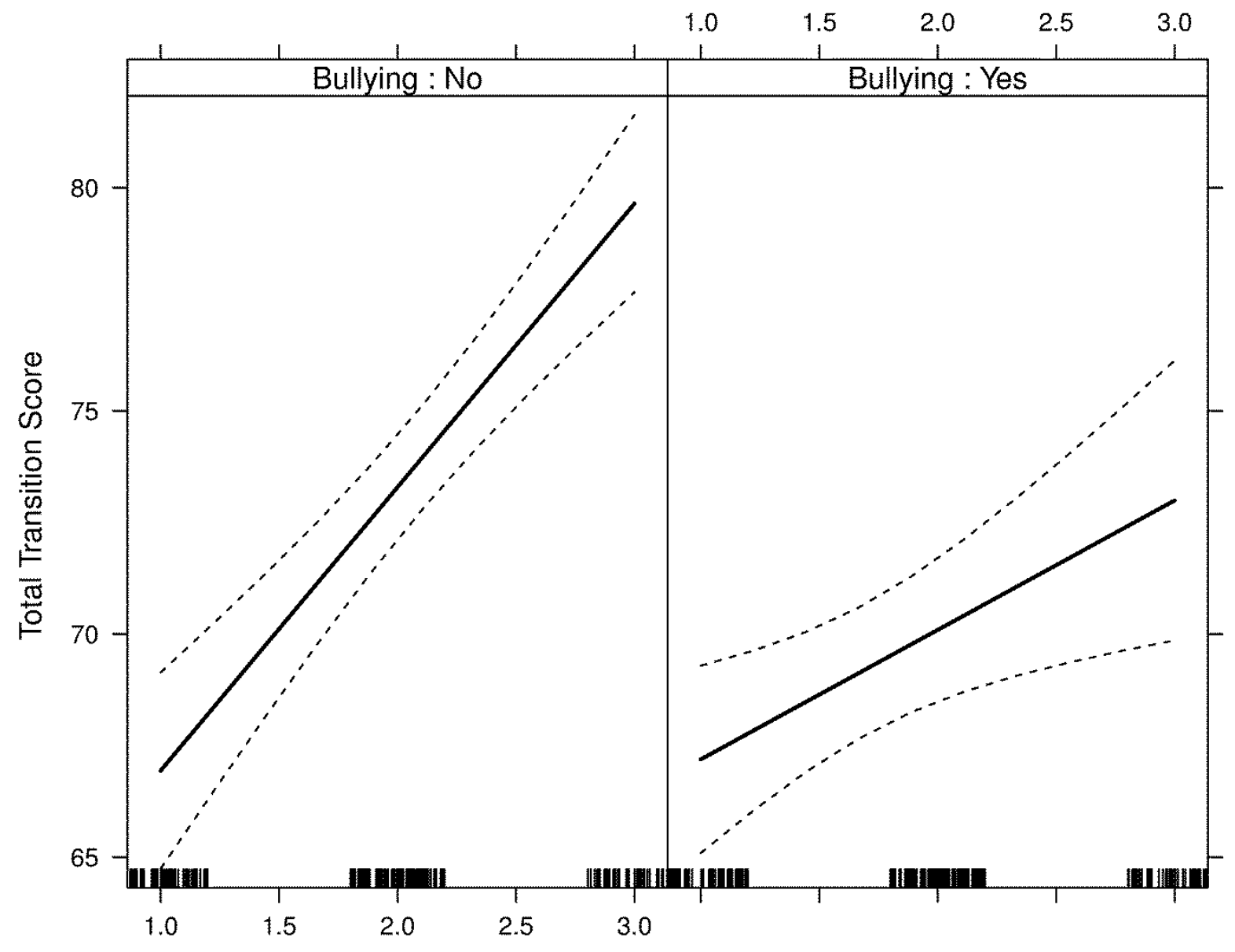

Ability to Access Support When Most Needed 